\title{
Studies on resources of genetic diversity in conservative flocks of geese using microsatellite DNA polymorphic markers
}

\author{
Rafał Parada • Juliusz Książkiewicz • \\ Magdalena Kawka • Kazimierz Jaszczak
}

Received: 17 June 2011/Accepted: 3 December 2011/Published online: 16 December 2011

(C) The Author(s) 2011. This article is published with open access at Springerlink.com

\begin{abstract}
The studies conducted aimed at evaluating the genetic diversity within and between varieties of conservative flocks of geese, using the polymorphism of 14 microsatellite sequences. The experimental material included conservative flocks of geese the following indigenous breeds and varieties kept in Poland: Kielecka (Ki), Kartuska (Ka), Lubelska (Lu), Suvalska (Su), Rypinska (Ry), Sub-Carpathian (SC), Hunched Beak (HB) and Pomeranian (Po). Among the 14 microsatellite sequences a total of 97 microsatellite alleles were identified. The number of alleles at one locus ranged from 3 to 19 . In the overall pool of 97 alleles, 26 (26.8\%) were specific for individual breeds and varieties of geese. The values of the expected heterozygosity $(\mathrm{He})$ for individual geese ranged from 0.38 (Sub-Carpathian) to 0.51 (HB). Similarly, the mean values for the observed heterozygosity (Ho) ranged from 0.45 (Po) to 0.55 ( $\mathrm{Ki}$ and $\mathrm{Su}$ ). The polymorphic information content reached the highest value of 0.80 at loci CKW21 (Ki) and TTUCG5 (Po and Su). The greatest genetic distance was observed between the $\mathrm{HB}$ and Ry (0.44) and between the HB and Po (0.39) varieties, while the smallest-between the $\mathrm{Lu}$ and $\mathrm{Po}$ as well as $\mathrm{Lu}$ and $\mathrm{Ki}$ (0.028) varieties. The phylogenetic tree, elaborated on the basis of the genetic distances, clearly confirms the specificity of the HB goose as compared to the remaining breeds and varieties.
\end{abstract}

R. Parada $(\varangle) \cdot$ M. Kawka $\cdot$ K. Jaszczak

Polish Academy of Sciences, Institute of Genetics and Animal Breeding, Jastrzebiec, 05-552 Wólka Kosowska, Poland

e-mail: R.Parada@ighz.pl

J. Książkiewicz

National Research Institute of Animal Production, Balice,

32-083 Krakow, Poland
Keywords Conservative flock - Geese - Genetic distance · Genetic diversity · Microsatellite markers

\section{Introduction}

The majority of native goose flocks have been included in the world's genetic resources (World Watch List for Domestic Animal Diversity, [15]). These internationally unique native populations of commercial birds are connected with, and very well adapted to, regions of Poland that differ climatically, environmentally and culturally. The birds are characterized by very good health and resistance to variable and often adverse climatic conditions, and good conversion of farm-produced feeds. They use open range and many varieties have retained the natural instinct for broodiness and looking after their young.

Reserve and conservative goose flocks constitute a unique material for research, rendering it possible to evaluate breeds and varieties already withdrawn from commercial production and included in protective programs. Small, isolated populations, such as reserve and conservative geese flocks, must be genetically stable. In a closed population there is a risk of an increased frequency of chromosome aberrations and decreased genetic variability, what may lead to, among much else, an inbreeding depression, i.e. lower production or lower resistance to diseases.

Literature data indicate that microsatellite markers are useful not only for the determination of heterozygosity and estimating the genetic distance between closely related populations or species $[1,6]$, but may also be used for determining genetic parameters such as the polymorphic information content (PIC), genetic diversity index between 
populations Fst and the identification of specific alleles $[2,8,13]$.

During the last years a majority of papers on the genetic variability in geese has been published by Chinese authors, evaluating numerous local varieties on the basis of microsatellite markers [9, 18, 19].

The research work conducted hitherto in Poland on the genetic diversity in conservative flocks of geese concentrated, among others, on the estimation of the phenotypic distance between flocks on the basis of the variability of protein fractions in blood plasma. However, methods based on immune response or electrophoresis, in which protein fractions are treated as genetic markers, make it possible to identify only about $25-35 \%$ of amino acid differences $[5,16]$. Work conducted using the DNA polymorphism (fingerprinting) in geese covered, among much else, the genetic analysis of the Zatorska goose and related varieties [22]. Bednarczyk [3], applying the RAPD-PCR method, observed a higher genetic variability in geese selected for body weight than in birds selected for egg production.

The present studies aimed at evaluating the genetic variability within and between varieties of local conservative flocks of geese, conducted with the use of the polymorphism of 14 microsatellite sequences.

\section{Materials and methods}

The experimental material came from conservative flocks of the following indigenous breeds and varieties of geese: Lubelska (Lu), Kielecka (Ki), Sub-Carpathian (SC), Hunched Beak (HB), Kartuska (Ka), Rypinska (Ry), Suvalska (Su) and Pomeranian (Po). Those flocks are maintained since the seventies without selection and avoiding inbreeding in the National Research Institute of Animal Production, Department of Water Fowl Breeding, Dworzyska.

Biological traits of geese from conservative flocks: resistance to illness, good quality of eggs (thick, strong shell), high reproductivity, longevity, adaptability to environmental conditions, ability to use less valuable feeds, docility, good muscling and low carcass fatness, very good feather quality.

Blood for the DNA isolation was drawn from the wing vein of 20 birds from each flock (160 birds a total). The DNA was isolated from blood with the use of the Wizard Genomic DNA Isolation KIT (Promega).

The polymorphism of 14 microsatellite sequences was analysed for three groups: CKW, TTUCG and MCW-one pair was marked by labelled with one of four stains: 6-FAM, VIC, NED, PET. A characteristic of the loci is presented in Table 1.

The amplification of selected microsatellite sequences was conducted using the thermocycler Engine PTC-200
(MJ Research). The PCR reaction was performed in $10 \mu \mathrm{l}$ of a mixture containing $10 \mathrm{ng}$ DNA matrix, $0.5 \mathrm{mM}$ of each nucleotide, 50 picomoles of each primer starter from a pair, $1.5 \mathrm{mM} \mathrm{MgCl}_{2}, 50 \mathrm{mM} \mathrm{KCl}, 10 \mathrm{mM}$ Tris- $\mathrm{HCl}$, $0.01 \%(w / v)$ Triton X-100 and 0.5 Units of DNA polymerase (Polgen). The PCR products were separated electrophoretically using a the four-capillary Applied Biosystems 3130 genetic analyzer and GeneScan Analysis software v 2.1. Moreover, the GeneMapper software of Applied Biosystems was used for the automatic determination of allele size for individual markers identified in the capillary sequenator ABI 3130.

The observed heterozygosity Ho was estimated for all the microsatellite loci examined in each population as the share of heterozygous genotypes in the overall pool of genotypes in a given population.

The expected heterozygosity He was estimated according to the formula by Ott [12] and Weir [20].

The polymorphic information content (PIC) was calculated according to Botstain [4]. The index of genetic variability between populations Fst was conducted using the FSTAT v.2.9.3 software. The same software was also used for calculating the Fis coefficient.

The genetic distance $\mathrm{D}_{\mathrm{A}}$ was calculated according to the method by Nei [10], using the DISPAN software [11]. The results obtained for the genetic distances were used to create a phylogenetic tree neighbor-joining $(\mathrm{N}-\mathrm{J})$, according to Saitou and Nei [14], applying the MEGA 4 software [17].

The level of the genetic variability between indigenous breeds and varieties of conservative flocks of geese was determined on the basis of three main parameters: number of alleles occurring at a given microsatellite loci, the share of microsatellite loci in the total number of loci examined (observed heterozygosity Ho) and the genetic variability index (Fst).

\section{Results and discussion}

Within the 14 microsatellite sequences examined a total of 97 alleles was identified. Among markers with the highest polymorphism one may count loci CKW21, at which 19 alleles were identified and TTUCG5, at which 18 alleles were observed (Table 2).

The number of alleles at one locus ranged from three (locus CKW14) to 19 (locus CKW21). At each of the microsatellite loci examined a mean of 6.92 alleles was recorded, what is similar to the values reported by other authors. Li et al. [9] analysing 31 microsatellites identified 218 alleles, what resulted in a mean per locus of 7.03. The highest mean number of alleles per locus was observed in the population of $\mathrm{Ka}$ (4.07) and $\mathrm{HB}$ (3.92) birds, while the 
Table 1 A characteristic based on GenBank of the 14 microsatellite DNA loci, selected for analyses

\begin{tabular}{|c|c|c|c|c|}
\hline Locus & Starter sequence $\left(5^{\prime}-3^{\prime}\right)$ & Length of alleles (bp) & Annealing temp $\left({ }^{\circ} \mathrm{C}\right)$ & GenBank accession number \\
\hline CKW14 & $\begin{array}{l}\text { AACTGATCCGGCAGAAAACTAA } \\
\text { ACTTAGCATGCAGCTTCACAAA }\end{array}$ & 275 & 59 & AY720927 \\
\hline CKW15 & $\begin{array}{l}\text { AGGCATGATATCTGTCCCTGAT } \\
\text { TTTCAGTGCAATTACCCATTCA }\end{array}$ & 277 & 55 & AY720926 \\
\hline CKW18 & $\begin{array}{l}\text { AATGTGCTGTGTCACATTCTCC } \\
\text { CATCATCCAACGATTCAGACAT }\end{array}$ & 335 & 52 & AY720929 \\
\hline CKW19 & $\begin{array}{l}\text { ACATGTCCTGAAGCATTTTCCT } \\
\text { TTCCTTTTCGCCTATGATGTCT }\end{array}$ & 276 & 59 & AY720930 \\
\hline CKW20 & $\begin{array}{l}\text { GATCAGAAATGAAGTGCAGACG } \\
\text { TGCTCCATTAATTATGCAACCTT }\end{array}$ & 265 & 55 & AY720931 \\
\hline CKW21 & $\begin{array}{l}\text { CCCAGAACAGTGCTAGAAGAGG } \\
\text { AGCGAGTCACTCCAGTACCTTC }\end{array}$ & 380 & 53 & AY722649 \\
\hline CKW41 & $\begin{array}{l}\text { CTAAGGTAGATTGTACATCAC } \\
\text { GCAGGTTAAACACGTTGTTCTG }\end{array}$ & 384 & 55 & AY787855 \\
\hline CKW45 & $\begin{array}{l}\text { TGAAACCAATTTTTCCCATTC } \\
\text { TCCTGGCCAATCCCATAGTA }\end{array}$ & 249 & 55 & AY790333 \\
\hline CKW46 & $\begin{array}{l}\text { GCAGCTGATGAGAAGCAGAA } \\
\text { GAGTGTGTGTGTGCGTCTGTT }\end{array}$ & 286 & 60 & AY790334 \\
\hline CKW48 & $\begin{array}{l}\text { AAATTGGGCCTAAGTTGCTACA } \\
\text { CAACTGGCTGTGGTTCTCCT }\end{array}$ & 244 & 56 & AY790336 \\
\hline TTUCG1 & $\begin{array}{l}\text { CCCTGCTGGTATACCTGA } \\
\text { GTGTCTACACAACAGC }\end{array}$ & 143 & 54 & U66089 \\
\hline TTUCG5 & $\begin{array}{l}\text { GGGTGTTTTCCAACTCAG } \\
\text { CACTTTCCTTACCTCATCTT }\end{array}$ & 204 & 58 & U66093 \\
\hline MCW4 & $\begin{array}{l}\text { GGATTACAGCACCTGAAGCCACTA } \\
\text { AAACCAGCCATGGGTGCAGATTGG }\end{array}$ & 214 & 63 & L40038 \\
\hline MCW264 & $\begin{array}{l}\text { AGACTGAGTCACACTCGTAAG } \\
\text { CTTACTTTTCACGACAGAAGC }\end{array}$ & 401 & 55 & G32032 \\
\hline
\end{tabular}

lowest in the SC variety (3.35). This indicates that the $\mathrm{Ka}$ and $\mathrm{HB}$ geese are characterized by the highest variability, while the SC birds show the lowest variability among the geese analysed.

In the total pool of 97 alleles, $26(26.8 \%)$ were specific for individual varieties of geese (Table 3). Specific alleles were observed in each of the eight breeds and varieties of geese analysed.

In the case of four microsatellite loci no specific alleles were found for any of the varieties of geese examined (CKW45, CKW48, TTUCG1, MCW264).

The HB geese were characterized by the greatest number of specific alleles (8), what indicates their genetic separateness. In turn, the lowest number of specific alleles was observed in the $\mathrm{Ki}$ and $\mathrm{Su}$ goose populations (1).

On the basis of the frequency observed for individual alleles at the 14 microsatellite loci a calculation was made of the expected heterozygosity $\mathrm{He}$, taking into consideration the number and frequency of alleles, and the observed heterozygosity Ho, which included heterozygous genotypes. Heterozygosity is an important parameter for estimating the genetic variability in the population, describes its genetic potential and adaptation abilities. The values for the observed heterozygosity Ho (Table 4), calculated jointly for a population including eight breeds and varieties of geese, ranged from 0.05 at locus CKW18 to 0.93 at locus CKW48. The mean value for Ho amounted to 0.50 at locus. The highest, mean for all loci values for observed heterozygosity (Ho), exceeding 0.5 were recorded for the $\mathrm{Ki}$ (0.55) and Lu geese (0.53), while the lowest for the Po birds (0.45), what was concordant with the values obtained for the polymorphic information content (PIC).

The values for the expected heterozygosity $\mathrm{He}$, estimated for the whole goose population analysed, ranged from 0.12 for locus CKW18 to 0.80 for locus CKW21. The mean expected heterozygosity amounted to 0.44 per locus. The highest $\mathrm{H}_{\mathrm{e}}$ values, mean for all loci, were observed for the HB goose (0.51), while the lowest (0.38) for the SC 
Table 2 The number of identified alleles and the mean number of alleles at one locus for individual goose breeds and varieties

\begin{tabular}{|c|c|c|c|c|c|c|c|c|c|}
\hline Variety & Ry & $\mathrm{Ka}$ & $\mathrm{SC}$ & $\mathrm{Ki}$ & $\mathrm{Lu}$ & $\mathrm{Su}$ & HB & Po & Total \\
\hline Number of birds & 20 & 20 & 20 & 20 & 20 & 20 & 20 & 20 & 160 \\
\hline CKW14 & 2 & 2 & 2 & 2 & 2 & 2 & 3 & 2 & 3 \\
\hline CKW15 & 3 & 3 & 3 & 2 & 3 & 4 & 5 & 3 & 5 \\
\hline CKW18 & 3 & 2 & 2 & 2 & 2 & 2 & 3 & 2 & 7 \\
\hline CKW19 & 3 & 2 & 2 & 3 & 2 & 3 & 2 & 3 & 4 \\
\hline CKW20 & 2 & 3 & 2 & 2 & 2 & 2 & 4 & 2 & 6 \\
\hline CKW21 & 7 & 11 & 7 & 12 & 8 & 9 & 9 & 8 & 19 \\
\hline CKW41 & 2 & 2 & 2 & 2 & 3 & 2 & 4 & 2 & 4 \\
\hline CKW45 & 3 & 5 & 4 & 3 & 4 & 5 & 6 & 3 & 6 \\
\hline CKW46 & 3 & 6 & 3 & 4 & 4 & 2 & 3 & 4 & 8 \\
\hline CKW48 & 3 & 2 & 2 & 2 & 3 & 4 & 3 & 2 & 4 \\
\hline TTUCG1 & 2 & 2 & 3 & 3 & 2 & 2 & 2 & 2 & 4 \\
\hline TTUCG5 & 7 & 10 & 9 & 6 & 11 & 8 & 5 & 10 & 18 \\
\hline MCW4 & 4 & 3 & 3 & 3 & 2 & 2 & 2 & 2 & 4 \\
\hline MCW264 & 4 & 4 & 3 & 2 & 4 & 3 & 4 & 4 & 5 \\
\hline Total & 48 & 57 & 47 & 48 & 52 & 50 & 55 & 49 & 97 \\
\hline Mean number of allele at locus & 3.42 & 4.07 & 3.35 & 3.42 & 3.71 & 3.57 & 3.92 & 3.5 & 6.92 \\
\hline
\end{tabular}

Ry Rypinska, Ka kartuska, SC sub-carpathian, Ki Kielecka, Lu Lubelska, Su Suvalska, HB Hunched Beak, Po Pomeranian

Table 3 Allele specific for given breeds and varieties of geese

\begin{tabular}{|c|c|c|c|c|c|c|c|c|}
\hline Microsatellite/variety & Ry & $\mathrm{Ka}$ & $\mathrm{SC}$ & $\mathrm{Ki}$ & $\mathrm{Lu}$ & $\mathrm{Su}$ & $\mathrm{HB}$ & Po \\
\hline CKW14 & - & - & - & - & - & - & 220 & - \\
\hline CKW15 & 240 & - & - & - & - & - & 222 & - \\
\hline CKW18 & $\begin{array}{l}236 \\
266\end{array}$ & - & 230 & 244 & - & - & - & 228 \\
\hline CKW19 & 226 & - & - & - & - & - & - & - \\
\hline CKW20 & - & 250 & 226 & - & - & - & 234 & - \\
\hline CKW21 & - & - & - & - & 240 & 228 & $\begin{array}{l}264 \\
272\end{array}$ & - \\
\hline CKW41 & - & - & - & - & - & - & 250 & - \\
\hline CKW45 & - & - & - & - & - & - & - & - \\
\hline CKW46 & - & $\begin{array}{l}212 \\
246\end{array}$ & - & - & 244 & - & - & 248 \\
\hline CKW48 & - & - & - & - & - & - & - & - \\
\hline TTUCG1 & - & - & - & - & - & - & - & - \\
\hline TTUCG5 & - & - & 230 & - & 240 & - & $\begin{array}{l}174 \\
234\end{array}$ & - \\
\hline MCW4 & 156 & - & - & - & - & - & - & - \\
\hline MCW264 & - & - & - & - & - & - & - & - \\
\hline Total & 5 & 3 & 3 & 1 & 3 & 1 & 8 & 2 \\
\hline
\end{tabular}

Ry Rypinska, Ka Kartuska, SC sub-carpathian, Ki Kielecka, Lu Lubelska, Su Suvalska, HB Hunched Beak, Po Pomeranian

birds. The values for heterozygosity, presented for conservative flocks of indigenous geese must be considered as low. Tu et al. [18] and Yunjie et al. [21], examining the genetic diversity in Chinese indigenous grey geese, reported a mean heterozygosity ranking from 0.49 to 0.69 .
The results presented indicate that among the varieties analysed the HB goose were characterized by the highest genetic variability (the highest values for heterozygosity, the highest number of allele and the highest number of specific alleles). 
Table 4 The observed (Ho) and expected (He) heterozygosity in the goose breeds and varieties examined

\begin{tabular}{|c|c|c|c|c|c|c|c|c|c|c|c|c|c|c|c|c|c|c|}
\hline \multirow[t]{2}{*}{ Locus } & \multicolumn{2}{|c|}{ Ry } & \multicolumn{2}{|c|}{$\mathrm{Ka}$} & \multicolumn{2}{|c|}{$\mathrm{SC}$} & \multicolumn{2}{|c|}{$\mathrm{Ki}$} & \multicolumn{2}{|c|}{$\mathrm{Lu}$} & \multicolumn{2}{|c|}{$\mathrm{Su}$} & \multicolumn{2}{|c|}{ HB } & \multicolumn{2}{|c|}{ Po } & \multicolumn{2}{|c|}{$\hat{\mathrm{H}}$ for locus } \\
\hline & $\mathrm{He}$ & Ho & $\mathrm{He}$ & Ho & $\mathrm{He}$ & Ho & $\mathrm{He}$ & Ho & $\mathrm{He}$ & Ho & $\mathrm{He}$ & Ho & $\mathrm{He}$ & Ho & $\mathrm{He}$ & Ho & $\hat{\mathrm{He}}$ & Ĥo \\
\hline CKW14 & 0.51 & 0.80 & 0.51 & 0.85 & 0.52 & 0.90 & 0.53 & 0.85 & 0.51 & 0.85 & 0.52 & 0.90 & 0.58 & 0.85 & 0.51 & 0.85 & 0.52 & 0.85 \\
\hline CKW15 & 0.68 & 0.68 & 0.59 & 0.70 & 0.61 & 0.85 & 0.48 & 0.70 & 0.61 & 0.80 & 0.72 & 1.0 & 0.57 & 0.70 & 0.64 & 0.75 & 0.61 & 0.77 \\
\hline CKW18 & 0.15 & 0.05 & 0.05 & 0.05 & 0.05 & 0.05 & 0.05 & 0.05 & 0.05 & 0.05 & 0.10 & 0.05 & 0.51 & 0.05 & 0.05 & 0.05 & 0.12 & 0.05 \\
\hline CKW19 & 0.16 & 0.05 & 0.05 & 0.05 & 0.10 & 0.10 & 0.42 & 0.10 & 0.05 & 0.05 & 0.19 & 0.20 & 0.34 & 0.05 & 0.35 & 0.05 & 0.20 & 0.08 \\
\hline CKW20 & 0.12 & 0.12 & 0.28 & 0.30 & 0.05 & 0.05 & 0.19 & 0.20 & 0.05 & 0.05 & 0.05 & 0.05 & 0.28 & 0.20 & 0.05 & 0.05 & 0.13 & 0.12 \\
\hline CKW21 & 0.63 & 0.60 & 0.85 & 0.65 & 0.79 & 0.85 & 0.87 & 0.90 & 0.75 & 0.74 & 0.90 & 0.65 & 0.85 & 0.55 & 0.78 & 0.65 & 0.80 & 0.69 \\
\hline CKW41 & 0.51 & 0.10 & 0.49 & 0.05 & 0.05 & 0.05 & 0.34 & 0.05 & 0.53 & 0.05 & 0.05 & 0.05 & 0.54 & 0.20 & 0.42 & 0.05 & 0.36 & 0.07 \\
\hline CKW45 & 0.54 & 0.40 & 0.46 & 0.40 & 0.15 & 0.15 & 0.32 & 0.35 & 0.39 & 0.45 & 0.50 & 0.30 & 0.74 & 0.55 & 0.15 & 0.05 & 0.40 & 0.33 \\
\hline CKW46 & 0.66 & 1.0 & 0.75 & 0.85 & 0.55 & 1.0 & 0.64 & 1.0 & 0.68 & 1.0 & 0.53 & 0.95 & 0.63 & 0.80 & 0.62 & 0.65 & 0.63 & 0.90 \\
\hline KW48 & 0.64 & 0.95 & 0 & 0.85 & 0.48 & 0.70 & 0 & 1 & 8 & 1 & 0.62 & 1. & 0.61 & 1 & .53 & 1 & 0.56 & 0.93 \\
\hline TTUCG1 & 0.10 & 0.10 & 0 . & 0. & 0.10 & 0.10 & 0.46 & 0.50 & 0.10 & 0.10 & 0.10 & 0.10 & 0.05 & 0.05 & 5 & 0.05 & 0.13 & 0.14 \\
\hline TTUCG5 & 0.84 & 0.88 & 0.83 & 1.0 & 0.86 & 1.0 & 0.82 & 1. & 0.84 & 1. & 0.87 & 0.95 & 0.29 & 0.25 & 0.87 & 0.95 & 0.77 & 0.87 \\
\hline MCW4 & 0.72 & 0.80 & 0.57 & 0.80 & 0.69 & 0.75 & 0.60 & 0.95 & 0.53 & 0.95 & 0.52 & 0.90 & 0.53 & 1.0 & 0.53 & 0.95 & 0.58 & 0.88 \\
\hline MCW264 & 0.36 & 0.30 & 0.32 & 0.35 & 0.32 & 0.35 & 0.15 & 0.15 & 0.39 & 0.35 & 0.56 & 0.65 & 0.74 & 0.60 & 0.35 & 0.20 & 0.39 & 0.36 \\
\hline$\hat{\mathrm{H}}$ for variety & 0.47 & 0.48 & 0.45 & 0.50 & 0.38 & 0.49 & 0.45 & 0.55 & 0.43 & 0.53 & 0.44 & 0.55 & 0.51 & 0.48 & 0.42 & 0.45 & 0.44 & 0.50 \\
\hline
\end{tabular}

Ry Rypinska, $K a$ Kartuska, $S C$ sub-carpathian, $K i$ Kielecka, $L u$ Lubelska, $S u$ Suvalska, $H B$ Hunched Beak, Po Pomeranian

The low level of heterozygosity may be explained by the use of three microsatellite loci of low polymorphicity (loci CKW18, CKW20, TTUCG1), what lead to a decrease of the values of both $\mathrm{He}$ and Ho. For a more comprehensive interpretation of the comparatively low level of heterozygosity and to eliminate Wahlund's effect (reduction of heterozygosity in a population caused by the merging of subpopulations with different allele frequencies within the sample examined) the inbreeding coefficient Fis was calculated (Table 5). The values obtained for Fis, calculated for the seven goose breeds and varieties examined, proved to be negative and in one case close to zero (HB). The values presented show there was no inbreeding in the goose populations examined.

Another parameter characterising the genetic variability and used to determine the value of markers in analysing the linkage with other loci is the polymorphism information Content (PIC). The PIC indicator showed the lowest value of 0.04 for locus: TTUCG1 (HB), CKW41 (Su), CKW18 (Po,

Table 5 Values of the inbreeding coefficient Fis

\begin{tabular}{lr}
\hline Varieties & \multicolumn{1}{l}{ Fis (SE) } \\
\hline Rypinska & $-0.02(0.13)$ \\
Kartuska & $-0.11(0.10)$ \\
Sub-Carpathian & $-0.27(0.08)$ \\
Kielecka & $-0.19(0.14)$ \\
Lubelska & $-0.22(0.12)$ \\
Suvalska & $-0.22(0.14)$ \\
Hunched Beak & $0.05(0.16)$ \\
Pomeranian & $-0.07(0.16)$
\end{tabular}

Ki, SC and Ka), CKW19 (Ka), CKW20 (Po, Su, Lu and SubCarpathian), while the highest value of 0.80 for locus: CKW21 (Ki) and TTUCG5 (Po and Su) (Table 6). According to Botstein et al. [4], values for coefficient PIC exceeding 0.50 indicate a highly informative locus, values ranking from 0.50 to $0.25-$ a medium informative locus, while values below 0.25-a not informative locus. Accepting Botstein's interpretation, four loci (CKW15, CKW21, CKW46 and TTUCG5) were characterized by a high, six loci (CKW14, CKW41, CKW45, CKW48, MCW4 and MCW264) by a medium and four loci (CKW18, CKW19, CKW20, TTUCG1) by a low PIC indicator.

One must emphasise that not all the microsatellite markers selected for analysis were characterized by a high polymorphism of heterozygosity or by high values of the polymorphism information content. Among the least polymorphic microsatellite markers one may count loci CKW18, CKW20 and TTUCG1.

The Fst index of genetic variability was calculated in order to evaluate the genetic variability between the populations examined.

The interpretation of results obtained for the Fst index were accepted after Hartl and Clark [7]. Values below 0.05 indicate a small differentiation between populations, values ranking between 0.05 and $0.15-\mathrm{a}$ medium variability, values ranking between 0.15 and $0.25-\mathrm{a}$ high variability, while values exceeding 0.25 indicate a very high differentiation between the populations compared. In the present study the values obtained for the Fst index ranged from 0.02 to 0.18 (Table 7). Basing on the interpretation presented, a small differentiation was observed between the Ka and Po 
Table 6 Polymorphism information content PIC for the microsatellite loci examined within the goose breeds and varieties analysed

\begin{tabular}{llllllllll}
\hline & Ry & Ka & SC & Ki & Lu & Su & HB & Po \\
\hline CKW14 & 0.36 & 0.36 & 0.37 & 0.37 & 0.36 & 0.37 & 0.47 & 0.36 & 0.37 \\
CKW15 & 0.59 & 0.48 & 0.49 & 0.35 & 0.49 & 0.62 & 0.50 & 0.54 \\
CKW18 & 0.13 & 0.04 & 0.04 & 0.04 & 0 & 0.09 & 0.42 & 0.04 & 0.1 \\
CKW19 & 0.14 & 0.04 & 0.09 & 0.34 & 0.04 & 0.17 & 0.26 & 0.30 & 0.17 \\
CKW20 & 0.10 & 0.23 & 0.04 & 0.16 & 0.04 & 0 & 0.25 & 0.04 & 0.10 \\
CKW21 & 0.56 & 0.78 & 0.72 & 0.80 & 0.67 & 0.83 & 0.77 & 0.71 \\
CKW41 & 0.35 & 0.35 & 0 & 0.26 & 0.39 & 0.04 & 0.44 & 0.31 \\
CKW45 & 0.46 & 0.38 & 0.13 & 0.28 & 0.32 & 0.43 & 0.66 & 0.13 \\
CKW46 & 0.55 & 0.67 & 0.41 & 0.53 & 0.57 & 0.37 & 0.51 & 0.53 \\
CKW48 & 0.54 & 0.36 & 0.35 & 0.37 & 0.44 & 0.50 & 0.49 & 0.37 \\
TTUCG1 & 0.04 & 0.12 & 0.09 & 0.39 & 0.09 & 0.09 & 0 & 0.31 \\
TTUCG5 & 0.76 & 0.74 & 0.78 & 0.74 & 0.76 & 0.80 & 0.26 & 0.42 \\
MCW4 & 0.62 & 0.46 & 0.58 & 0.47 & 0.37 & 0.37 & 0.37 & 0.80 \\
MCW264 & 0.32 & 0.28 & 0.28 & 0.12 & 0.34 & 0.46 & 0.65 & 0.37 \\
Mean & 0.39 & 0.38 & 0.31 & 0.37 & 0.35 & 0.37 & 0.43 & 0.30 \\
\hline
\end{tabular}

Ry Rypinska, $K a$ Kartuska, SC sub-carpathian, $K i$ Kielecka, Lu Lubelska, Su Suvalska, $H B$ Hunched Beak, Po Pomeranian

Table 7 Genetic variability index Fst for the goose breeds and varieties analysed

\begin{tabular}{|c|c|c|c|c|c|c|c|}
\hline & Ry & $\mathrm{Ka}$ & $\mathrm{SC}$ & $\mathrm{Ki}$ & $\mathrm{Lu}$ & $\mathrm{Su}$ & $\mathrm{HB}$ \\
\hline $\mathrm{Ka}$ & 0.035 & & & & & & \\
\hline $\mathrm{SC}$ & 0.072 & 0.062 & & & & & \\
\hline $\mathrm{Ki}$ & 0.045 & 0.027 & 0.081 & & & & \\
\hline $\mathrm{Lu}$ & 0.041 & 0.043 & 0.107 & 0.039 & & & \\
\hline $\mathrm{Su}$ & 0.033 & 0.027 & 0.053 & 0.024 & 0.033 & & \\
\hline $\mathrm{HB}$ & 0.120 & 0.138 & 0.187 & 0.124 & 0.135 & 0.128 & \\
\hline Po & 0.023 & 0.020 & 0.072 & 0.026 & 0.021 & 0.028 & 0.153 \\
\hline
\end{tabular}

Ry Rypinska, Ka Kartuska, SC sub-carpathian, Ki Kielecka, Lu Lubelska, Su Suvalska, HB Hunched Beak, Po Pomeranian

Table 8 Genetic distance $\mathrm{D}_{\mathrm{A}}$ between the goose breeds and varieties analysed

\begin{tabular}{lllllll}
\hline & Ry & Ka & SC & Ki & Lu & HB \\
\hline Ka & 0.107 & & & & \\
SC & 0.127 & 0.042 & 0.043 & 0.037 & & \\
$\mathrm{Ki}$ & 0.132 & 0.063 & 0.067 & 0.052 & & \\
$\mathrm{Lu}$ & 0.200 & 0.034 & 0.028 & 0.028 & 0.046 & 0.298 \\
$\mathrm{Su}$ & 0.083 & 0.344 & 0.254 & 0.298 & 0.321 & 0.067 \\
$\mathrm{HB}$ & 0.446 & 0.042 & 0.062 & 0.081 & 0.062 & 0.394 \\
Po & 0.128 & & & & \\
\hline
\end{tabular}

Ry Rypinska, $K a$ Kartuska, $S C$ sub-carpathian, $K i$ Kielecka, Lu Lubelska, $S u$ Suvalska, $H B$ Hunched Beak, Po Pomeranian

goose varieties $($ Fst $=0.02)$, and a considerable differentiation between the $\mathrm{SC}$ and $\mathrm{HB}$ varieties $(\mathrm{Fst}=0.18)$. Most common was a small diversity between varieties -15 goose pairs, next a medium variability -11 goose pairs and in the case of two pairs - a high variability.

In order to determine the degree of genetic diversity between individual goose breeds and varieties the genetic distance $\mathrm{D}_{\mathrm{A}}$ was calculated (Table 8 ). The greatest value for the genetic distance was observed between the $\mathrm{HB}$ and Ry varieties (0.44), as well as the HB and Po (0.39), while between the $\mathrm{Su}$ and $\mathrm{SC}$ and $\mathrm{Su}$ and $\mathrm{Ki}$ the lowest values were observed (0.028).

HB geese, compared with the remaining varieties analysed, demonstrated the highest values of $\mathrm{D}_{\mathrm{A}}$ and thus a 


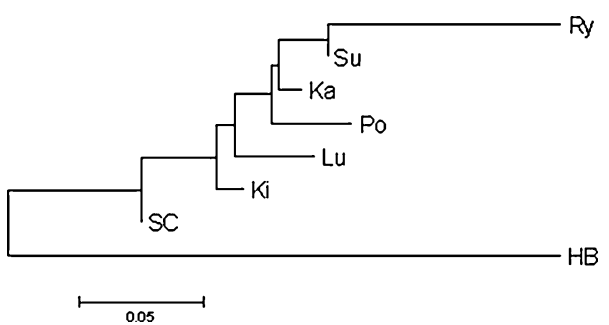

Fig. 1 Phylogenetic tree neighbor-joining (N-J) for eight goose breeds/ varieties, created on the basis of the values obtained for $\mathrm{D}_{\mathrm{A}}$ distance

certain evolution separateness. This confirms the presented earlier results, obtained for the genetic diversity index (Fst), which also indicate a mean or considerable differentiation between the HB goose and the remaining goose breeds and varieties analysed.

The phylogenetic tree (Fig. 1), obtained on the basis of the genetic distances $\left(\mathrm{D}_{\mathrm{A}}\right)$, clearly confirms the separateness of the HB goose from the remaining seven goose varieties and a certain similarity of groups with the regional origin of birds.

The phylogenetic tree presented groups together the Ry with $\mathrm{Su}$ varieties and $\mathrm{Po}$ with $\mathrm{Ka}$, what indicates their region of origin (Po, Ka, Ry-Northern Poland; SC, Ki, $\mathrm{Lu}-$ Southern Poland). A similar result, reflecting the origin and mutual relations linking the varieties examined, was presented by Zawadzka [22], who calculated the genetic distance on the basis of the similarity indices for DNA fingerprinting patterns.

The presented separateness of the HB goose arises from its origin, as it was created by crossing of Anser domesticus with an East-Asian goose, originating from the Chinese Anser cygnoides goose, while the remaining varieties come from the Anser anser.

The diversity between the varieties examined can be considered as medium. The highest diversity was observed between the varieties $\mathrm{HB}, \mathrm{Su}, \mathrm{Ki}$ and $\mathrm{Lu}$ (highest heterozygosity values, a large mean number of allele at locus), while the lowest between the SC and Po varieties.

The highest differentiated genetic variability potential was observed for the HB and Su geese.

Acknowledgment This study was supported by grants no. N311 013233 from the Ministry of Science and Higher Education, Poland.

Open Access This article is distributed under the terms of the Creative Commons Attribution Noncommercial License which permits any noncommercial use, distribution, and reproduction in any medium, provided the original author(s) and source are credited.

\section{References}

1. Azam A, Babar ME, Firyal S, Anjum AA, Akhtar N, Asif M, Hussian T (2011) DNA typing of Pakistani cattle breeds
Tharparkar and Red Sindhi by microsatellite markers. Mol Biol Rep. doi:10.1007/s11033-011-0807-1

2. Bartfai R, Egedi S, Yue GH, Kovacs B, Urbanyi B, Tamas G, Horvath L, Orban L (2003) Genetic analysis of two common carp broodstocks by RAPD and microsatellite markers. Aquaculture 219:157-167

3. Bednarczyk M, Siwek M, Mazanowski A, Czekalski P (2002) DNA polymorphism in various goose lines by RAPD-PCR. Folia Biologica (Kraków) 50:45-48

4. Botstain D, White RL, Skolnick M, Dawid RW (1980) Construction of a genetic linkage map in man using restriction fragment length polymorphisms. Am J Hum Genet 32:314-331

5. Brodacki A, Smalec E (2001) Genetic polymorphism of slowmigrating prealbumin in geese. Electron J Pol Agric Univ Seria AH 4(2): 10

6. Chen GH, Wu XS, Wang DQ, Qin J, Wu SL, Zhou QL, Xie F, Cheng R, Xu Q, Liu B, Zhang XY, Olowofeso O (2004) Cluster analysis of 12 Chinese native chicken populations using microsatellite markers. Asian Australas J Animl Sci 17:1047-1052

7. Hartl DL, Clark AG (1997) Principles of population genetics, 3rd edn. Sinauer Associates, Sunderland

8. Kawka M, Parada R, Jaszczak K, Horbańczuk JO (2011) The use of microsatellite polymorphism in genetic mapping of the ostrich (Struthio camelus). Mol Biol Rep. doi:10.1007/s11033-011-1107-5

9. Li HF, Chen KW, Yang N, Song WT, Tang QP (2007) Evaluation of genetic diversity of Chinese native geese revealed by microsatellite markers. World Poult Sci 63:381-390

10. Nei M, Tajima F, Tateno Y (1983) Accuracy of estimated phylogenetic trees from molecular data. II. Gene frequency data. J Mol Evol 19:153-170

11. Ota T (1993) DISPAN. Institute of Molecular Evolutionary Genetics. The Pensylwania State University, University Park

12. Ott J (1992) Strategies for characterizing highly polymorphic markers in human gene mapping. Am J Hum Genet 51:283-290

13. Rohrer GA, Alexander LJ, Keele JW, Smith TP, Beattie CW (1994) A microsatellite linkage map of the porcine genome. Genetics 136:231-245

14. Saitou N, Nei M (1987) The neighbor-joining method: a new method for reconstructing phylogenetic trees. Mol Biol Evol 4:406-425

15. Scherf BD (2000) World Watch List for Domestic Animal Diversity, 3rd edn. FAO, Rome

16. Smalec E (1991) Differentiation geese genetic reserve in terms of utilities and blood serum protein polymorphism. Appl Sci COBRD Poznan 3:5-87

17. Tamura K, Dudley J, Nei M, Kumar S (2007) MEGA4: Molecular Evolutionary Genetics Analysis (MEGA) software version 4.0. Mol Biol Evol. doi:10.1093/molbev/msm092

18. Tu YJ, Chen KW, Zhangs SJ, Tang QP, Gao YS, Yang N (2006) Genetic Diversity of 14 Indigenous Grey Goose Breeds in China Based on Microsatellite Markers. Asian Australas J Anim Sci $19: 1-6$

19. Wang JW, Qiu XP, Zeng FT, Shi XW, Zhang YP (2005) Genetic differentiation of domestic goose breeds in China. J Genet Genomics 32:1053-1059

20. Weir BS (1990) Genetic data analysis: methods for discrete population genetic data. Massachusetts: Sinauer Associates, Inc, Sunderland

21. Yunjie T, Kuanwei C, Qingping T, Jinyu W, Yushi G, Rong G, Qinglian G (2006) Genetic diversity of 13 indigenous grey goose breeds in China based on microsatellite markers. Biodiversity Sci 14:152-158

22. Zawadzka M (1999) Genetic analysis of the Polish native Zatorska Goose and related varieties by DNA fingerprinting. Ph.D. thesis, Polish Acad Sci, Inst Genet Anim Breed, Jastrzębiec, Poland 